\section{OPTIMIZATION OF THE DEVELOPED OUTER SURFACE OF AN INDUSTRIAL OIL COOLER} ELENA SERGEEVNA BAYMETOVA ${ }^{1}$, MARIA RAVILEVNA
KOROLEVA ${ }^{2}$, ALENA ALEKSEEVNA CHERNOVA ${ }^{1}$, MICHAL
KELEMEN $^{3}$

${ }^{1}$ Federal State Budget Educational Institution of Higher Education "Kalashnikov Izhevsk State Technical University", Russia

${ }^{2}$ Federal State Budgetary Scientific Institution "Udmurt Federal Research Center of the Ural Branch of the Russian Academy of Sciences", Russia

${ }^{3}$ Technical University of Kosice, Faculty of Mechanical Engineering, Department of Mechatronics, Slovakia

DOI: 10.17973/MMSJ.2021_10_2021027 e-mail to corresponding author : koroleva@udman.ru

ABSTRACT

Heat removal from the working liquid of hydraulic systems requires the use of heat exchange devices - oil coolers with their geometry directly affecting their efficiency. This paper considers the issues of statement and implementation of the numerical experiment to solve the optimization problem for the industrial oil design.

KEYWORDS mathematical modelling, conjugate heat exchange problem, optimization problem, oil coolers, cooling system

\section{INTRODUCTION}

In industry, various types of technical oils are commonly used as working liquids, designed to reduce the resistance of moving parts of mechanisms, and to increase their durability and maintain the temperature mode. In operation, the oil heats up; therefore, it is necessary to remove heat by installing an oil cooler, the geometry of which directly affects the thermal efficiency of the device [Tsygankov 2013]. Currently, the problem of choosing the form of oil cooler ribbing, as well as optimizing their design parameters, remains relevant because of the wide industrial use of hydraulic units and electric motors [Hruzik 2019, Kozubkova 2019]. Their functioning is impossible without sufficient cooling due to overheating of elements and, as a consequence, their subsequent deformation and destruction [Taradai 2003, Zhinov 2013, Dmitriev 2017].

\section{DESCRIPTION OF OIL COOLER}

The main structural element of oil coolers is still an aluminium or brass tube of the rectangular cross-section ribbed on its outer surfaces (Fig. 1). Technologies for the production of such structural elements of the oil cooler are different, as well as the range of applicability of the obtained tubes and their thermal physical properties [Turtelli 2006, Murcinkova 2013].

Ribbing is necessary to increase the effective heat exchange area, through which the heat will be removed into the environment. One of the most effective ribbing techniques is shaping or strain-cutting. Heat-exchange tubes made by this method have significant overall dimensions and, consequently, the higher weight of the product. The frequency of ribbing and the basic geometric characteristics of a single rib significantly affect both the device's thermal efficiency and its metal intensity. On this basis, the problem of optimizing the developed outer surface of tubes (both the shape of a single rib and technological parameters of shaping) is relevant.
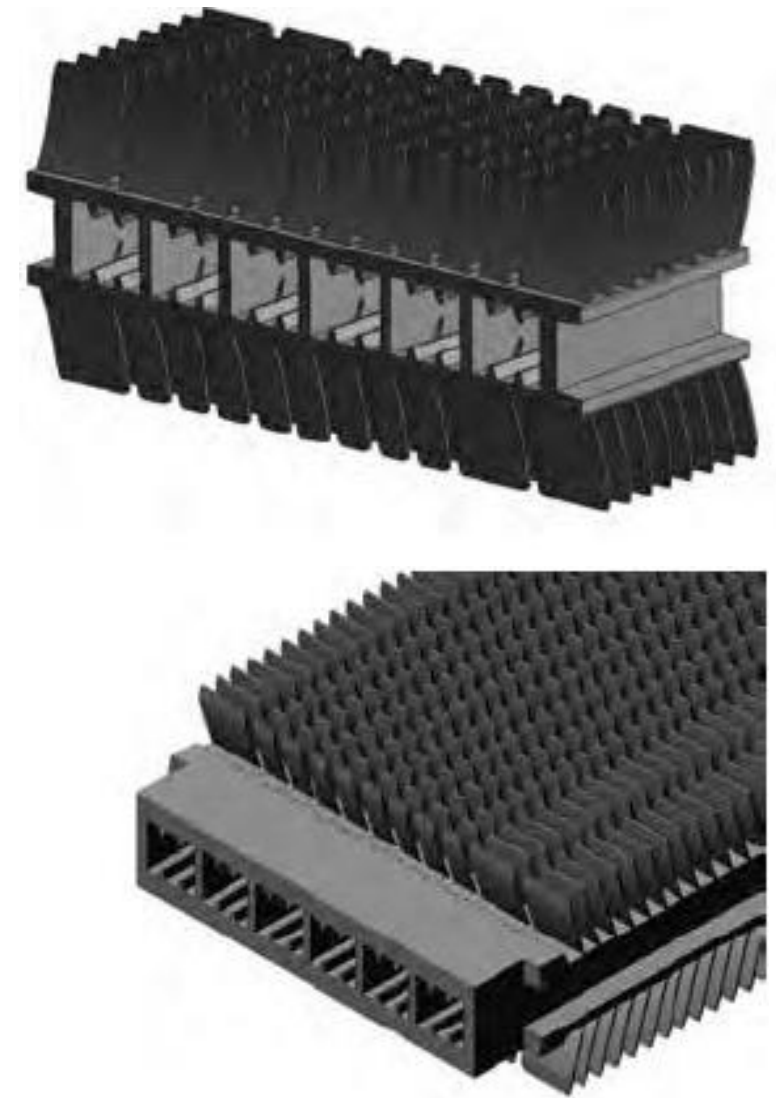

$$
\begin{array}{lllll}
0 & 7.5 & 15.0 & 22.5 & 30.0
\end{array}
$$

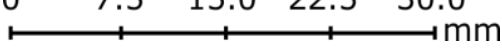

Figure 1. Elements of the cooling section

\section{OPTIMIZING OF OIL COOLER GEOMETRY}

The object of the study is a multi-section collector with a complex cross-sectional shape of liquid supply channels and with a developed outer surface for effective cooling of the heating agent [Salakhov 2017]. The cross-section of the element of the developed outer surface is shown in Figure 2.

The cooling section (Fig. 2) is made in the form of a flat tube with longitudinal inner channels of the rectangular crosssection, in which additional longitudinal ribs are placed to provide machine oil flow turbulence. It allows intensifying the heat exchange between the viscous medium and metal wall by preventing the formation of a laminar boundary layer. The heat exchanger's outer surface is equipped with double-sided multiple ribs to increase the device heat efficiency. However, according to [Khaibullina 2016, Zhinov 2013, Golovanchikov 2015], additional complications of the developed outer surface can have a negative impact on the economic efficiency of the oil cooler.

The paper solves the problem of optimizing the geometry of the developed outer surface of an industrial oil cooler by methods of computational mechanics.

The preliminary analysis of the developed outer surface of the oil cooler allowed to identify the most promising design parameters for optimization. Geometrically, the outer surface 
of the oil cooler is a series of thin ribs arranged normally to the channel surface. Forced blowing with cold air provides cooling of the outer surface of the oil cooler, thus increasing the liquid/wall heat transfer efficiency. However, the influence of design parameters on the cooling process requires further research and is a potential method for optimizing the oil cooler design. Therefore, several control parameters have been selected for further study in the first stage of optimization of the geometry of the oil cooler outer surface (Fig. 3).
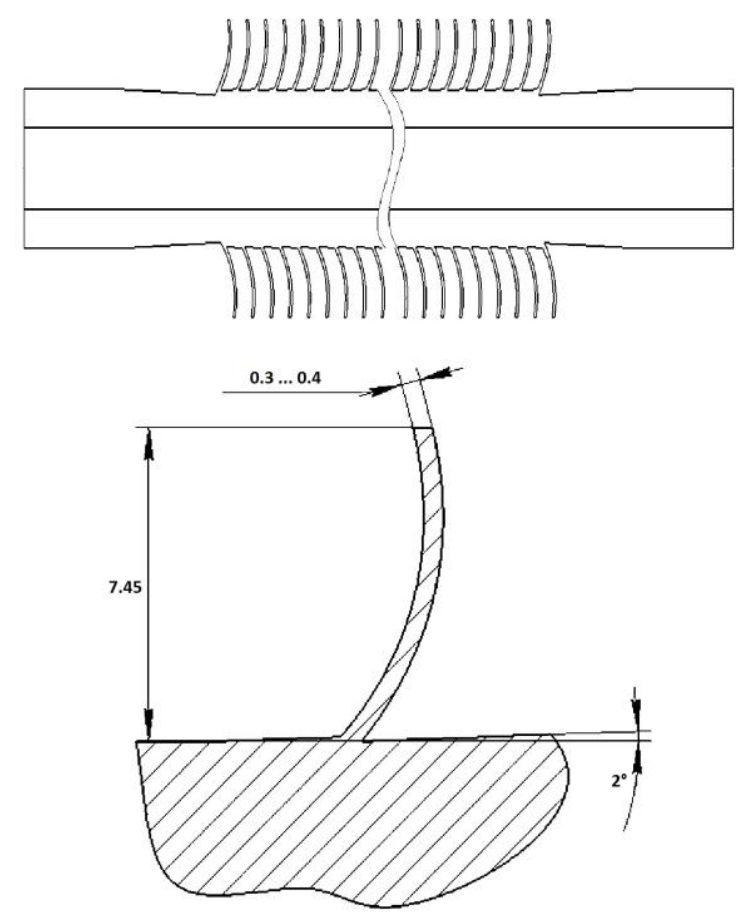

Figure 2. The element of the developed outer surface

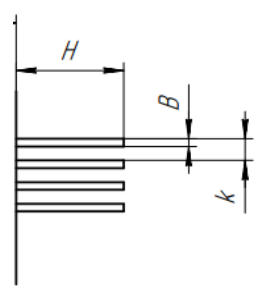

\begin{tabular}{|c|c|c|}
\hline Parameter & $\begin{array}{c}\text { Minimum } \\
\text { value, } \mathbf{~ m m}\end{array}$ & $\begin{array}{c}\text { Maximum } \\
\text { value, } \mathbf{~ m m}\end{array}$ \\
\hline$B$ & 0.3 & 0.4 \\
\hline$H$ & 7.45 & 7.45 \\
\hline$k$ & 2.3 & 20.4 \\
\hline$L$ & 2 & 20 \\
\hline
\end{tabular}

Figure 3. Control parameters of the oil cooler

At the first stage, numerical experiment methods are used to study the processes of heat transfer from the uniformly heated wall to the air when flowing around the paired ribs of a single cooling section to determine its thermal-hydraulic characteristics [Weller 2021, Theisen 2018, Yau 2016, Alletto 2019, Avila 2021, Zhukauskas 1982].

When making a mathematical model of the process of the oil cooler ribs cooling by an incoming air [Cernecky 2015] flow, the following assumptions were used:

1. We consider a small segment of the oil cooler, including two ribs; boundaries of the outer region are determined by nonreflective boundary conditions.

2. The plate material is isotropic, thermal conductivity processes are not taken into account. The outer surface temperature is determined by the working liquid temperature in the channel, i.e., the liquid/metal heat transfer processes are assumed to be instantaneous, and the heating is uniform.

3. In view of the duration of the considered processes and their operation in stationary modes, we consider stationary processes of air flowing around the oil cooler ribs and convective heat exchange [Cernecky 2015, Dmitriev 2017].

4. The influence of the oil cooler outer surface profile is taken to be insignificant; therefore, the material roughness is not considered.

5. At the first stage of the optimization problem solution, we study the influence of the distance between ribs of the developed outer surface of the oil cooler (the value of the parameter $L$ ) on the temperature distributions in the control sections of the calculation area. The step of parameter $L$ variation is $2 \mathrm{~mm}$

The mathematical model of liquid motion is based on NavierStokes equations. Gas motion modes in accordance with the Reynolds numbers $(20000<\operatorname{Re}<400000)$ correspond to the turbulent range, that is why the turbulence model SST [Menter 2003] was added to simulate the gas flow. The system of equations describing the motion of continuous media in the general case is as follows [Lipanov 2019, Koroleva 2020]:

$$
\begin{aligned}
& \frac{\partial \rho}{\partial t}+\frac{\partial \rho u_{i}}{\partial x_{i}}=0 \\
& \frac{\partial \rho u_{i}}{\partial t}+\frac{\partial \rho u_{i} u_{j}}{\partial x_{j}}=-\frac{\partial p}{\partial x_{i}}+\frac{\partial}{\partial x_{j}}\left(\mu\left(\frac{\partial u_{i}}{\partial x_{j}}+\frac{\partial u_{j}}{\partial x_{i}}\right)-\frac{2}{3} \mu \frac{\partial u_{k}}{\partial x_{k}} \delta_{i j}\right)+F_{i} \\
& \frac{\partial \rho E}{\partial t}+\frac{\partial \rho E u_{j}}{\partial x_{j}}=-\frac{\partial p u_{j}}{\partial x_{j}}+\frac{\partial u_{i} \tau_{i j}}{\partial x_{j}}+\frac{\partial q_{j}}{\partial x_{j}}+F_{i} u_{i}
\end{aligned}
$$

$p=\rho R T$

Modelling of heat transfer processes in the ribbed tube is carried out based on the heat conduction equation:

$\rho c_{p} \frac{\partial T}{\partial t}=\nabla \cdot(\lambda \nabla T)$

Boundary conditions of the problem are as follows:

- for the inlet section and the upper boundary, the velocity and temperature of the incoming flow are set;

- for the outlet section, conditions of zero gradient for the velocity and temperature and the fixed pressure value are assigned;

- for solid surfaces, conditions of adhesion for the velocity and zero gradient for the pressure, and the assigned temperature of the working surface are set.

The variable parameter is the distance between ribbing elements in the range of $L=2 \ldots 20 \mathrm{~mm}$ with $2 \mathrm{~mm}$ steps. The considered ribbing section is flown around by the cold air flow, which cools the plate due to convective heat transfer. Initial conditions are:

- the plate and rib temperature $T p=40 \ldots 60{ }^{\circ} \mathrm{C}$;

- the air temperature $T a=15 \ldots 25^{\circ} \mathrm{C}$;

- the air velocity $V a=10 \ldots 20 \mathrm{~m} / \mathrm{s}$.

When constructing a computational grid, a previously made sketch of the oil cooler element is used; the developed outer surface of the oil cooler has been placed into a cube denoting the boundaries of the calculation area. Notches in the cube obtained by ribbing elements have been used to form the final calculation area, and a grid has been made (Fig. $4 a$ ):

- grid elements are tetrahedrons;

- rib dimensions are $\max =0.001 \mathrm{~m}, \min =0.0001 \mathrm{~m}$;

- the maximum dimension near ribbing elements is $\max =$ $0.0015 \mathrm{~m}$.

The process of blowing occurs normally to the developed outer surface of the oil cooler. Figure $4 \mathrm{~b}$ shows the calculation lines: - Line 1: calculation at the inlet of the developed outer surface 
- Line 2: calculation at the outlet of the zone of the developed outer surface

- Line 3: calculation in the longitudinal inter-rib cross-section To evaluate the effectiveness, we make temperature profiles on the plate surface between ribbing elements: in crosssectional (Figure 4b, lines 1,2 ) and longitudinal (Figure $4 b$, line 3) directions in the section between ribbing elements for different inter-rib distances $B-k$.

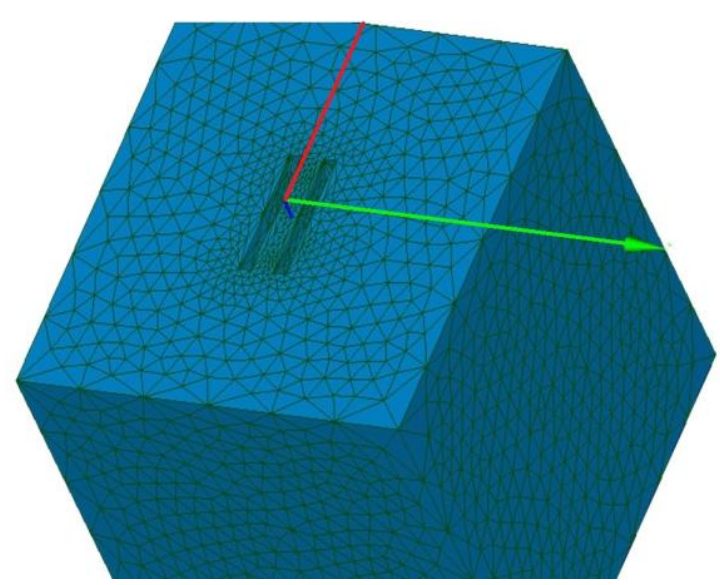

a)

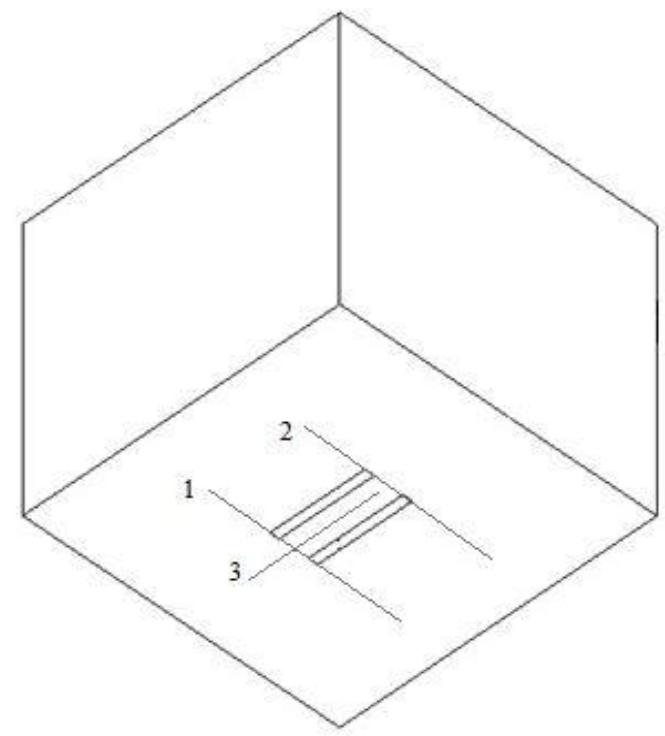

b)

Figure 4. a) calculation grid, b) calculation lines considered sections 1-3

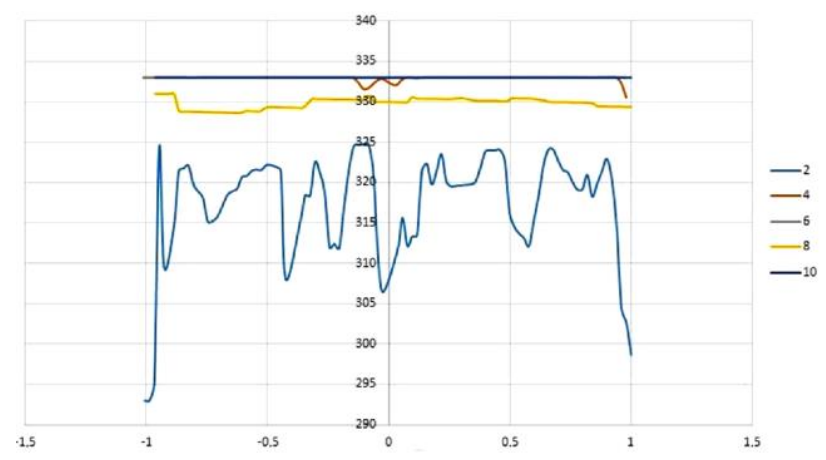

Figure 5. Temperature profiles in the longitudinal section between ribbing elements

The data analysis allowed revealing the ineffective range of variation of the inter-rib distance $L=10 \ldots 20 \mathrm{~mm}$.
Simultaneously, longitudinal temperature variations at $L<4$ are characterized by significant heterogeneity, which is unacceptable in the real device.

To clarify the influence of the inter-rib distance $L$ on the efficiency of heat removal from the ribbed surface, the relative temperature profile in the cross-section (by the coordinate $z / z_{\max }$ ) is received and analyzed (Fig. 6)

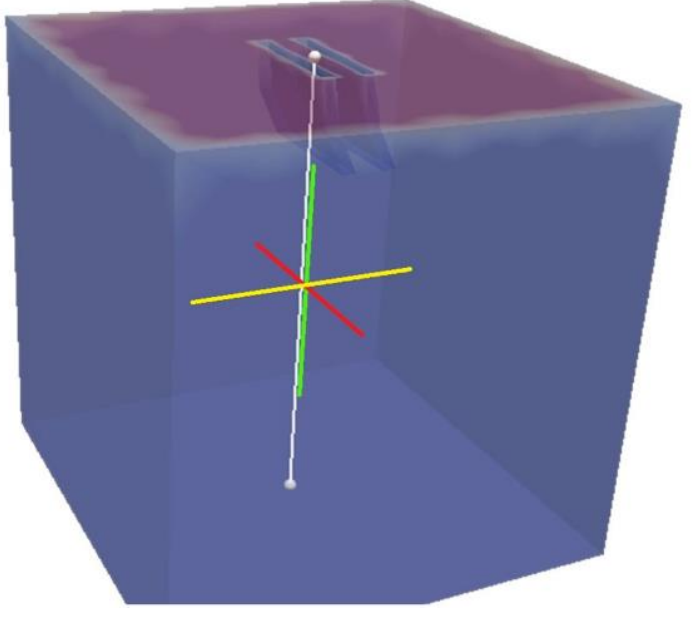

a)

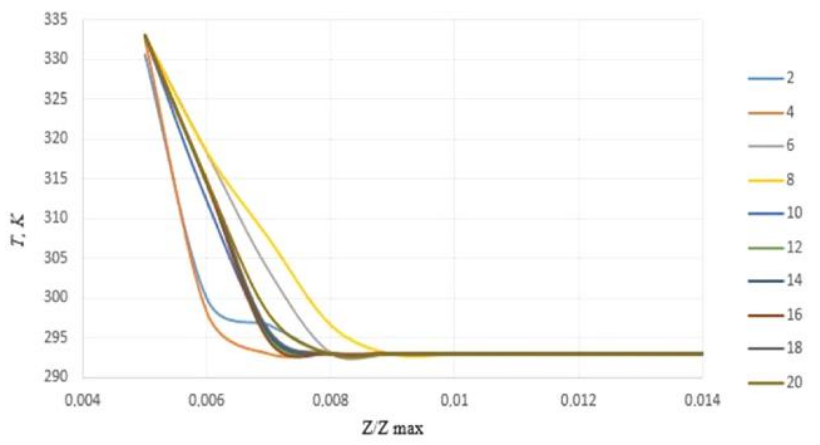

b)

Figure 6. a) Line of measurement b) Temperature distribution in the cross-section

Analysis of changes in cross-sectional temperature profiles on the inter-rib distance allows identifying a zone of heat fluxes' mixing - a zone of the intense heat exchange not exceeding $1.2 k$. Figure $6 \mathrm{~b}$ shows that the inter-rib distance significantly affects the rate of heat removal from the oil cooler surface. The angle $\gamma$ of the temperature limit determined by the heat exchange intensity given in Table 1 can be assessed by the approximation dependence on the inter-rib distance as:

\begin{tabular}{|l|l|l|}
\hline$L$ & $L H$ & $Y$ \\
\hline 2 & 0.268456 & 70.608 \\
\hline 4 & 0.536913 & 76.43084 \\
\hline 6 & 0.805369 & 63.10748 \\
\hline 8 & 1.073826 & 63.10748 \\
\hline 10 & 1.342282 & 68.96769 \\
\hline 12 & 1.610738 & 68.96769 \\
\hline 14 & 1.879195 & 68.96769 \\
\hline 16 & 2.147651 & 68.96769 \\
\hline 18 & 2.416107 & 68.96769 \\
\hline 20 & 2.684564 & 68.96769 \\
\hline
\end{tabular}

Table 1. Calculation the angle of the temperature limit 
Figure $6 \mathrm{~b}$ shows that when the distance between the elements $L=8 \mathrm{~mm}$, the temperature reduction due to the change in height is maximum; that is, the heated air layer is the narrowest in this case.

Let us also consider the temperature distribution at the boundary of the air flow inlet and outlet; lines along which it will be studied are shown in Figure 4 as 1 and 2. In this case, we will get the temperature change along the $y$ axis. Based on the calculated data, we plotted the diagrams in relative and absolute values.

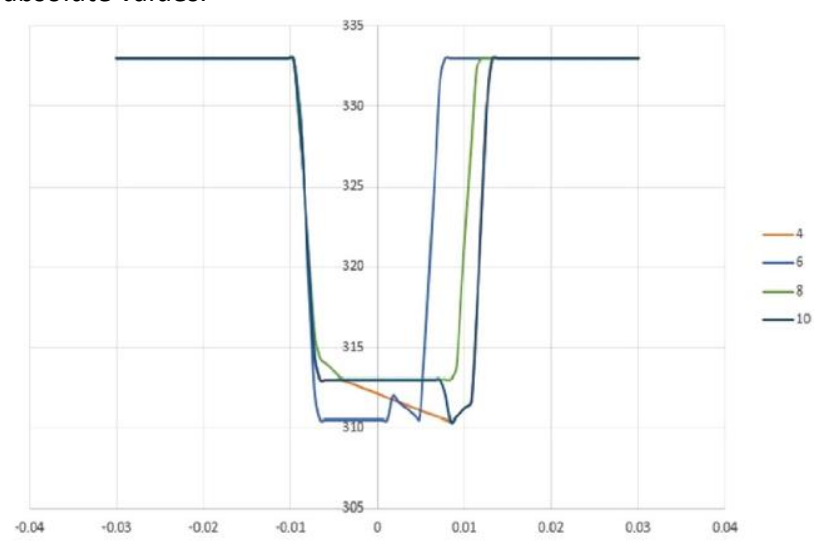

a)

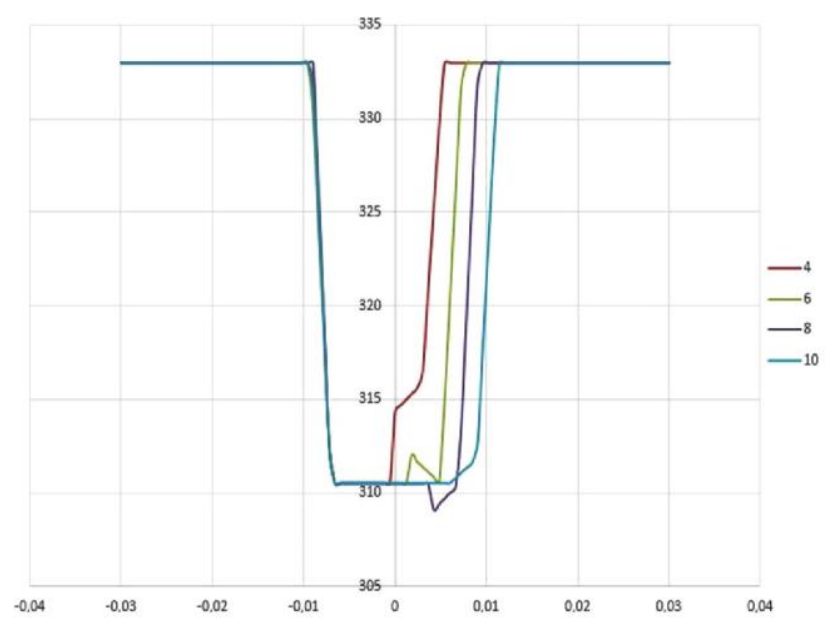

b)

Figure 7. a) temperature distribution at the inlet of the inter-rib space with absolute temperature values; $b$ ) temperature distribution at the outlet of the inter-rib space with absolute temperature values.

Figures 4-7 show that maximum cooling on this line prevails at inter-rib distances $L=4 \mathrm{~mm}$ and $L=8 \mathrm{~mm}$.

As a result, distributions of fields of the velocity, pressure, temperature, and heat flow near impermeable surfaces of the considered segment of the outer ribbing of the oil cooler are calculated; integral thermal physical characteristics of the air flow before and after the passage of ribbing elements depending on the size of the varied inter-rib spacing are obtained. The analysis of the obtained thermal physical characteristics, including the temperature profiles, allowed identifying the optimal (in terms of the oil cooler thermal efficiency) distance between ribbing elements, which is $8 \mathrm{~mm}$.

Therefore, numerical experiment methods and the solution of the problem of air cooling for paired ribs of a single cooling section allowed to optimize the geometry of the group of ribbing elements.
The authors consider that the mathematical model of air flow cooling of the ribbing element group and the proposed step-bystep approach to solving the multi-parameter nonlinear problem of optimizing the oil cooler design is novel in this work. The proposed mathematical model allowed to obtain the correlation between the control design parameter and the oil cooler thermal efficiency and to reveal the optimal distance between ribbing elements.

\section{ACKNOWLEDGMENTS}

The research was carried out with the financial support of Kalashnikov ISTU within the framework of the scientific project No. 4AA/20-30-07. The authors would like to thank the Slovak Grant Agency-project KEGA 030TUKE-4/2020 and VEGA 1/0389/18.

\section{REFERENCES}

[Alletto 2019] Alletto, M. OpenFOAM: The Open Source CFD Toolbox. OpenFOAM Foundation. [online]. Date of latest edit: April 23rd 2019. <URL address> https://openfoamwiki.net/index.php/ChtMultiRegio nFoam [date of citing March 22, 2021].

[Avila 2021] Avila, L. ParaView. Kitware, Inc., New York/Headquarters, Clifton Park, New York 12065 USA. [online]. <URL address> https://www.paraview.org/ [date of citing March 22, 2021].

[Cernecky 2015] Cernecky, J., Valentova, K., Pivarciova, E., Božek, P. Ionization impact on the air cleaning efficiency in the interior. In Measurement Science Review, 2015, Vol. 15, No. 4, pp. 156-166.

[Dmitriev 2017] Dmitriev A.V., Dmitrieva O.S. Heat exchange in the counter flow around of rows of tubes of the air cooler apparatus. Bulletin of the Technological University, 2017, Vol. 20, No. 13. pp. 40-43.

[Golovanchikov 2015] Golovanchikov A.B., Vorotneva S.B., Dulkin B.A., Kolomiets S.R., Kolomiets D.R. Effect of heat transfer surface ribbing on the efficiency of the two-pipe heat exchange device. Izvestiya VolgGTU. Ser. Rheology, Processes and Apparatuses of Chemical Technology, 2015, Iss. 8, No. 1, pp. 80-85.

[Hruzik 2019] Hruzik, L., et al. Valve control of drive with rotary hydraulic motor. MM Science Journal, 2019, pp. 2902-2909. DOI: 10.17973/MMSJ.2019_06_201882.

[Khaibullina 2016] Khaibullina, A.I., Ilyin, V.K. Increasing the efficiency of heat exchange in lubrication systems of pump-power units. Power Engineering, 2016, pp. 103-116.

[Koroleva 2020] Koroleva, M., Mischenkova, O., Kelemen, M., Chernova, A. Theoretical research of the internal gas dynamics processes of measurements of hot air curtain with cross-flow fan. MM Science Journal, 2020, pp. 3966-3972. DOI: 10.17973/MMSJ.2020_06_2020028.

[Kozubkova 2019] Kozubkova, M., Jablonska, J., Bojko, M., Dvorak, L., Carnogurska, M. Multiphase fluid models to deal with fluid flow dynamics. MM Science Journal, 2019, pp. 2891-2896. DOI: 10.17973/MMSJ.2019_06_201880.

[Lipanov 2019] Lipanov, A.M., Dadikina, S.Yu., Shumikhin, A.A., Koroleva, M.R., Karpov, A.I. Numerical simulation intra-chamber of unsteady turbulent flows stimulate - Part 1. Bulletin of the South Ural State University. Series "Mathematical Modelling, 
Programming and Computer Software", 2019, pp. 32-43. DOI: 10.14529/MMP190103.

[Menter 2003] Menter F.R., Kuntz M., Langtry R. Ten years of industrial experience with the SST turbulence model. In: Hanjalić, K. (Ed.), Proc. 4th. Int. Symp. On Turbulence, Heat and Mass Transfer. Begell House, 2003, p. 8.

[Murcinkova 2013] Murcinkova Z., Krenicky T. Implementation of virtual instrumentation for multiparametric technical system monitoring. In: SGEM 2013: 13th Int. Multidisciplinary Sci. Geoconf. Vol. 1: 16-22 June, 2013, Albena, Bulgaria. Sofia: STEF92 Technology, 2013. pp. 139-144. ISBN 978-95491818-9-0.

[Salakhov 2017] Salakhov R.R. Calculation of heat exchange devices with the outer ribbing. Report on research work. - Kazan, 2017. 68 p

[Taradai 2003] Taradai A.M., Kovalenko L.M., Gurin E.P. To the question of estimating the thermal energy efficiency of heat exchange devices used in municipal heat supply, Heat Supply News, 2003, No. 6, pp. 40-43.

[Theisen 2018] Theisen, L. Automated Boundary Layer Mesh Generation for Simulation of Convective Cooling. RWTH Aachen University, Aachen, 2018.
[Tsygankov 2013] Tsygankov M.P., Kruchinin D.S. Features of mathematical modeling of high-temperature heat exchange devices. Chemistry and Chemical Technology, 2013, Vol. 56, Issue 3, pp. 95-99.

[Turtelli 2006] Turtelli R.S., et al. Magnetic and structural characterization of as-cast and annealed melt- spun Fe80-xSi20Crx. Journal of Magnetism and Magnetic Materials, 2006, Vol. 304, No. 2, pp. E687-E689.

[Weller 2021] Weller, H. et al. "OpenFoam. Free CFD Software." [online]. <URL address> http://openfoam.org/ [date of citing March 22, 2021]

[Yau 2016] Yau, L.C. Conjugate Heat Transfer with the Multiphysics Coupling Library preCICE. Technische Universit at Munchen, 2016, 88 p.

[Zhinov 2013] Zhinov A.A., Shevelev D.V., Ananyev P.A. Modeling of air pressure losses in the ribbed tube bundle of the air condenser. Science and Education, 2013, No. 3, DOI: 10.7463/0313.0544307.

[Zhukauskas 1982] Zhukauskas A.A. Convective transfer in heat exchange devices. Moscow: Nauka, 1982, 472 p.

\section{CONTACTS:}

Maria R. Koroleva Ph.D., Associate Professor

Udmurt Federal Research Center,

Ural Branch, Russian Academy of Science,Baramzinoy str., 34,

426000, Izhevsk, Russian Federation,

koroleva@udman.ru 